\title{
Integrated Health Approaches to Pain Management and PTSD with Adolescent Gun-Shot-Wound Survivors: How Do We Treat the Whole Person?
}

\author{
Sean E Snyder* \\ Penn Medicine; Ena Cade, MD, Corizon Health, USA
}

Submission: January 08, 2020; Published: January 30, 2020

*Corresponding author: Sean E Snyder, MSW, LCSW, Penn Medicine; Ena Cade, MD, Corizon Health, USA

\begin{abstract}
Integrative healthcare approaches are known to improve patient outcomes by delivering systematic and cost-effective approaches to care. Adolescents who survive gunshot wounds present with a complex constellation of symptoms, both physically and psychologically, and require a systematic approach to their recovery. Collaboration between primary care providers and behavioral health providers allows for treatment of the whole person, including pain management, physical recovery, and psychological recovery. This case report highlights an integrated care approach between a pediatrician and a licensed clinical social worker, offering suggestions to maximize care under pain management recommendations
\end{abstract}

Keywords: Integrative health; Collaborative care model; Pain management; Trauma; Adolescent health

\section{Introduction}

The following review will highlight behavioral health approaches to foster psychological and physical recovery for adolescents following their discharge from an emergency department. The collaboration of physical and mental health care, often labeled as "integrative health care" or the "collaborative care model," has improved outcomes for patients by using a defined, systematic, and cost-effective approach to care [1]. Those who survive intentional violence or other types of injury present unique treatment considerations. Considering the collaborative care model, patient care would focus on three domains: recovery from the physical trauma itself, management of pain after injury, and management of psychological distress from injury.

\section{Violence, pain, and PTSD}

Community violence can be considered an epidemic considering that two thirds of urban youth have experienced physical violence victimization, with suburban youth reporting less but still signification levels of victimization [2]. Youth with such victimization are at risk for psychological trauma symptoms like hyperarousal, sleep difficulty, changes in mood or cognition which impact recovery on all fronts $[3,4]$. They are also more prone to further victimization [5] or drastically at risk for becoming perpetrators of violence themselves [6]. The presence of pain along with psychological trauma symptoms require systemic, targeted care. Pain is described as the "unpleasant sensory and emotional experience associated with actual or potential tissue damage or described in terms of such damage," which is often an adaptative response to injury and subsides with appropriate care [7]. The problem of pain is evidenced by data that indicates that $32 \%$ of youth with chronic pain, i.e., pain that persists past 3 months, report comorbid PTSD [8]. This comorbidity has significant repercussions, as high rates of comorbidity are known to correlate to higher levels of pain intensity and psychological problems and substance use [9-11].

\section{Pain management recommendations}

The CDC Guidelines for Prescribing Opioids for Chronic Pain specifically address the treatment of acute pain. Pain medications should be prescribed at the lowest effective dose for the shortest duration possible. In the face of the opioid epidemic, CDC guidelines state that, for acute pain, opioids should be ideally prescribed for 3 days, and no longer than 7 days [12]. They further recommend that non-pharmacological methods be employed as well. These methods are ideally provided by a skilled mental health clinician, who collaborates with the primary care provider 
providing feedback on the patient's on-going perceived level of pain. For those youth who progress to complain of chronic pain, on-going treatment using non-pharmacological methods is the preferred modality [12].

\section{Behavioral health approaches to pain management}

Behavioral health approaches can support recovery, specifically with pain management and PTSD symptoms. Cognitive behavioral approaches have been known to promote successful outcomes for patients recovering from intentional injury ${ }^{13}$. Such factors focus on thoughts related to pain and the traumatic event, as well as the behavioral responses. Patients with "pain catastrophizing" will appraise their pain more intensely, and this is mediated by their feelings of fear [14]. To coach these children, acceptance strategies are best. Relaxation skills found effective for teenagers include sensory soothing techniques (e.g., aromatherapy, mindful eating), focused breathing, progressive muscle relaxation, and general mindfulness techniques [15]. Coping thoughts include "Pain is managed, not cured- this will pass," "The more I fight the pain, the more it will persist," "Pain is not re-injury. Pain is a signal for me to take care of myself." Statements like the latter help patients to increase self-efficacy and confidence, with the hope of mobilizing a relaxation strategy. Pain-rating scales can help benchmark pain and serve as a way to show a pain hierarchy, both of which can limit the potential for cognitive bias in a patient's negative appraisals of pain [16].

\section{Case application}

James is 15-year-old male treated for a gunshot wound of his lower back, seen by detention nursing staff for necessary follow-up and referred to behavioral health care for management of his pain and post-traumatic stress symptoms. His structured assessments for pain and PTSD completed with the LCSW were in clinically significant ranges. James was provided psychoeducation about PTSD and behavioral approaches to pain management like relaxation skills. Treatment consisted of developing positive coping skills in the presence of his PTSD symptoms and pain symptoms. He also worked to develop a cognitive connection between the two symptom clusters. James' favorite relaxation skill he learned was mindful eating. He would be given a hard candy and was instructed to experience it mindfully, paying attention to the taste, texture, hardness and other features related to the candy itself. He was instructed to slow and control his breathing during this practice. He was able to use lessons to this skill when he would feel extreme pain or a trauma reaction e.g., an intrusive thought, which was a method to divert attention from the unwanted experience to a positive experience. He also enjoyed playing with kinetic sand and doing aromatherapy, delivered in the same didactic as the mindful eating exercise. Once James was able to modulate his feelings and stress level appropriately, he was coached to accept pain, knowing that he would be able to handle it. He was able to manage without the use of opioids and was given ibuprofen as his primary pain reliever. At his six months follow up, James reported drastically fewer PTSD symptoms and reported better ability to manage any leftover pains he felt.

\section{Discussion}

Collaboration between a primary care provider and behavioral health clinician are integral to the pain management of an adolescent. This care coordination helps with subjective and objective reports of pain, which allows for the best path of treatment for an adolescent. Adolescents admitted to a local detention center post gunshot wound often arrive shortly after the trauma, and the youth often arrive with prescriptions for opioid medications. Incarcerated youth are at a higher risk of drug dependence and abuse, underscoring the important of teaching them skills in pain management that do not include the use of opioid medications [17]. Adolescents who survive gunshot wounds present with a complex constellation of symptoms, both physically and psychologically, and require a systematic approach to their recovery. Collaboration between primary care providers and behavioral health providers allows for treatment of the whole person, including pain management, physical recovery, and psychological recovery. The case study illustrates that care can be effectively provided in a residential setting, and these successes can be translated to the outpatient setting through continued warm hand-offs, and open lines of communication between providers. This study warrants attention for further research into the particular mechanisms that facilitate positive treatment outcomes for youth with comorbid pain and psychological trauma symptoms.

\section{Conflict of interest}

The authors do not have financial conflict of interest or any conflict of interest to report.

\section{References}

1. Raney LE (2015) Integrating primary care and behavioral health: The role of the psychiatrist in the collaborative care model. American Journal of Psychiatry 172(8): 721-728.

2. Fein, Kassam-Adams, Gavin, Huang, Blanchard, Datner (2002) Persistence of posttraumatic stress in violently injured youth seen in the emergency department. Arch Pediatr Adolesc Med 156(8): 836840 .

3. Diagnostic and statistical manual of mental disorders: DSM $5^{\text {th }}$ Edn.

4. Corbin TJ, Purtle J, Rich LJ, Rich JA, Adams EJ, Yee G, et al. (2013) The prevalence of trauma and childhood adversity in an urban, hospitalbased violence intervention program. J Health Care Poor Underserved 24(3): 1021-1030.

5. Smith DJ, Ecob R (2007) An investigation into causal links between victimization and offending in adolescents. Br J Sociol 58(4): 633-659.

6. Chang JJ, Chen JJ, Brownson RC (2003) The role of repeat victimization in adolescent delinquent behaviors and recidivism. J Adolesc Health 32(4): 272-280. 
7. Kind S, Otis JD (2019) The interaction between chronic pain and PTSD. Curr Pain Headache Rep 23(12): 91.

8. Noel M, Wilson AC, Holley AL, Durkin L, Patton M, Palermo TM (2016) Posttraumatic stress disorder symptoms in youth with vs without chronic pain. Pain 157(10): 2277-2284.

9. Jenewein J, Wittmann L, Moergeli H, Creutzig J, Schnyder U (2009) Mutual influence of posttraumatic stress disorder symptoms and chronic pain among injured accident survivors: A longitudinal study. J Trauma Stress 22(6): 540-548.

10. Outcalt SD, Kroenke K, Krebs EE, Chumbler NR, Wu J, Yu Z, et al. (2015) Chronic pain and comorbid mental health conditions: Independent associations of posttraumatic stress disorder and depression with pain, disability, and quality of life. J Behav Med 38(3): 535-543.

11. Sullivan MJL, Thibault P, Simmonds MJ, Milioto M, Cantin A, Velly AM (2009) Pain, perceived injustice and the persistence of post-traumatic stress symptoms during the course of rehabilitation for whiplash injuries. Pain 145(3): 325-331.
12. Dowell D, Haegerich TM, Chou R (2016) CDC Guidelines for Prescribing Opioids for Chronic Pain-US, 2016. MMWR Recomm Rep 65(1): 1-49

13. Fein Joel A, Mollen Cynthia J, Greene (2013) The assault-injured youth and the emergency medical system: What can we do? Clinical Pediatric Emergency Medicine 14(1): 47-55.

14. Vlaeyen J, Morley S, Linton SJ, Boersma K, de Jong J (2012) Pain-related fear: exposure based treatment for chronic pain ( $1^{\text {st }}$ ed.). Seattle (WA): IASP Press.

15. Snyder SE (2018). Implementation of trauma-focused cognitivebehavioral therapy in juvenile detention: A practice note from the field. Practice Innovations 3(4): 284-294.

16. Rusu AC, Gajsar H, Schlüter M, Bremer Y (2019) Cognitive biases toward pain: Implications for a neurocognitive processing perspective in chronic pain and its interaction with depression. Clin J Pain 35(3): 252-260.

17. (2011) Health Care for Youth in the Juvenile Justice System Pediatrics 128(6): 1219-1235.

\section{Your next submission with Juniper Publishers} will reach you the below assets

- Quality Editorial service

- Swift Peer Review

- Reprints availability

- E-prints Service

- Manuscript Podcast for convenient understanding

- Global attainment for your research

- Manuscript accessibility in different formats ( Pdf, E-pub, Full Text, Audio)

- Unceasing customer service

Track the below URL for one-step submission https://juniperpublishers.com/online-submission.php 